\title{
PENGARUH GAYA KEPEMIMPINAN DAN LINGKUNGAN KERJA TERHADAP DISIPLIN KERJA PEGAWAI KECAMATAN KANOR KABUPATEN BOJONEGORO
}

\author{
Bayu Sentosa \\ Program Studi Manajemen, Fakultas Ekonomi, Universitas Islam Darul Ulum Lamongan \\ bayu.sentosa@unisda.ac.id \\ Nurul Fauziah \\ Program Studi Manajemen, Fakultas Ekonomi, Universitas Islam Darul Ulum Lamongan \\ nurul_fauziyah@unisda.ac.id
}

\section{Tholiatul Mas'adah}

Program Studi Manajemen, Fakultas Ekonomi, Universitas Islam Darul Ulum Lamongan

Tholiatulmasadah22@gmail.com

\begin{abstract}
This research is motivated by the lack of optimal work discipline of Kanor District Office staff in Bojonegoro Regency. The purpose of this study was to describe (1) the influence of the sub-district leadership style in the Kanor District Office in Bojonegoro district, (2), and the work environment towards the work discipline of the Kanor District Office staff in Bojonegoro, (3) the influence of leadership style and work environment on work discipline employees in the employee work environment in Kanor district, Bojonegoro district. The method used in this study is quantitative with the type of Explanatory Research. The population in this study amounted to 20 employees. A sample of 20 employees was determined using Simple Random Sampling. Data was collected through questionnaires, interviews and documentation. The results of the study show (1) the work discipline of the Kanor District of Bojonegoro Regency is at a moderate level or the quality is quite good. (2) Leadership style has a positive effect on employee work discipline at Kanor District Office in Bojonegoro Regency (3) The working environment is very influential on the work discipline of Kanor District Office staff in Bojonegoro Regency
\end{abstract}

Keywords: Employee Discipline Leadership Style, Work Environment

\section{PENDAHULUAN}

Suatu organisasi disiplin menjadi faktor yang sangat penting dalam rangka mewujudkan tujuan - tujuannya, karena tanpa didasari oleh kondisi disiplin yang baik suatu organisasi tidak mungkin dapat mencapai efektivitas dan efesiensi yang tinggi. Pelaksanaan otonomi daerah akan berdampak pada kesiapan pemerintah daerah dalam mengatur sistem pemerintahannya agar tercipa pelayanan publik efektif, efisiensi, dan terbuka bagi publik serta dapat berperan penting dalam penyelenggaraan

pemerintahannya.Penyelenggaraan pemimpin daerah diarahkan dengan tujuan dengan pelayanan yang baik, pemberdayaan dalam masyarakat yang antusias untuk meningkatkan daya saingberdasarkan demokrasi berkeadilan daan kesatuan Negara Indonesia

Salah satu nilai kepribadian yang menunjang terbentuknya Sumber Daya Manusia ( SDM) yang berkualitas yaitu disiplin dan kedisiplinan. Disiplin ditunjukkan oleh semua lapisan masyarakat dan seluruh aparatur pemerintah demi tercapainya tujuan. Disiplin yang dilakukan oleh pemerintah yang akan di implementasikan oleh pegawai daerah , sehingga baik pemerintahan pusat ataupun pemerintahandaerah bersinergi untuk keteraturan. Aparatur kecamatan akan mengingatkan kualitas pelayanan terhadap 
masyarakat di pembinaan kedisiplinan terhadap aparatur pemerintah dikantor kecamatan dilakukan agar tumbuh kesadaran dalam mensukseskan aturan yang di buat. Kurangannya kedisiplinan akan menghambat penyelenggaraan roda pemerintahan kecamatan yang secara tidak langsung akan mempengaruhi jalannya sebuah pemerintahan secara keseluruhan. Kedisiplinan dari pegawai merupakan penentu dalam keberhasilan sebuah organisasi yang bertujuan mencapai apa yang diharapkan, kedisiplinan pegawai sangat berpengaruh dalam pencapaian - pencapaian tujuan organisasi. Rumusan masalah adalah sebagai berikut :

1. Bagaimana gaya kepemimpinan camat terhadap disiplin kerja pegawai di kecamatan Kanor kabupaten Bojonegoro?

2. Bagaimana lingkungan kerja terhadap disiplin kerja pegawai kecamatan Kanor kabupaten Bojonegoro?

3. Bagaimana pengaruh gaya kepemimpinan dan lingkungan kerja terhadap disiplin kerja pegawai kecamatan Kanor kabupaten Bojonegoro?

\section{KAJIAN TEORI}

\section{A. Pengertian Motivasi}

Rivai (2014:42) menyatakan Gaya Kepemimpinan adalah sekumpulan ciri yang digunakan pimpinan untuk memengaruhi bawahan agar sasaran organisasi tercapai atau dapat pula dikatakan bahwa gaya kepemimpinan adalah pola perilaku dan strategi yang disukai dan sering diterapkan oleh seorang pemimpin. SedangkanSoekarso (2010), gaya kepemimpinan adalah perilakuatau tindakan seorang pemimpin dalam melaksanakan tugastugas pekerjaan manajerial.Dapat disimpulkan bahwa gaya kepimpinan adalah sikap seorang pemimpin dalam menjalankan tugasnya dan memotivasi anggotanya untuk berprestasi Terdapat berbagai gaya kepemimpinan, yaitu:

1. Gaya Kepemimpinan Otoriter/Authoritarian

$$
\text { Gaya kepemimpinan otoriter }
$$

adalah gaya pemimpin yang memusatkansegala keputusan dan kebijakan yang diambil dari dirinya sendiri secara penuh.Segala pembagian tugas dan tanggung jawab dipegang oleh si pemimpin yangotoriter tersebut, sedangkan anggota hanya menjalankan tugas yang di berikan.

2. Gaya kepemimpinan Demokratis/ Democratic

Gaya kepemimpinan demokratis adalah gaya pemimpin yang memberikanwewenang secara luas kepada para bawahan..ketika ada masalah anggota di ikutsertakan dalam penyelesaian masalah. Dalam kepemimpinan demokratis pemimpin memberi ruang untuk menyelesaikan tugas yang di berikan

3. Gaya Kepemimpinan Bebas/Laissez Faire Gaya kepemimpinan bebas ini pemimpinan terlibat dalam kuantitas yang kecil di mana para bawahannya yang secara aktif menentukan tujuan danpenyelesaian masalah yang dihadapi.

\section{B. Pengertian Lingkungan Kerja}

Khairani Sofyan (2013: 20), lingkungan kerja adalah segala sesuatu yang berada di sekitar karyawan yang mempengaruhi dirinya dalam menjalankan dan menyelesaikan tugas-tugas yang diberikan kepadanya dalam suatu wilayah. Sedangkan Sari Andam dewi (2013: 211) bahwa, lingkungan kerja yang kondusif memungkinkan pegawai bekerja lebih bersemangat, sehingga hasil kerjanya lebih memuaskan.

\section{Pengertian Displin Kerja}

Indah (2014:182), mengatakan bahwa disiplin merupakan suatu keadaan tertentu di mana orang-orang yang tergabung dalam organisasi tunduk pada peraturan-peraturan yang ada rasa senang hati. Sedangkan menurut Singodimedjo dalam (Edi, 2009:86), mengatakan bahwa disiplin adalah sikap kesediaan dankerelaan seseorang untuk mematuhi dan mantaati norma-norma peraturan yangberlaku disekitarnya. Disiplin kerja merupakan alat yang digunakan para manajeruntuk berkomunikasi dengan karyawan agar mereka bersedia untuk mengubahsuatu perilaku serta sebagai upaya untuk meningkatkan kesadaran dan kesediaan seseorang menanti semua peraturan perusahaan dan norma-norma sosial yang berlaku.

Penulis merumuskan hipotesis sebagai berikut: 
H1: Gaya kepemimpinan berpengaruh positif signifikan terhadap disiplin kerja pegawai.

$\mathrm{H} 2$ : Lingkungan kerja berpengaruh positif signifikan terhadap disiplin kerja pegawai.

H3: Gaya kepemimpinan dan lingkungan kerja berpengaruh secara bersama - sama terhadap disiplin kerja pegawai pada Kecamatan Kanor Kabupaten Bojonegoro.

\section{METODE PENELITIAN}

Penelitian ini menggunakan pendekatan penelitian kuantitatif dengan jenis penelitian Explanatory Research. Pendekatan kauntitatif merupakan penelitian yang dilakukan untuk menjelaskan hubungan kausal antara variabel-variabel melalui pengujian hipotesa yang dirumuskan. Menurut sugiyono (2013: 13), metode penelitian kuantitatif dapat diartikan sebagai metode penelitian yang berlandaskan pada filsafat positivme, digunakan untuk meneliti pada populasi atau sampel tertentu, teknik pengambilan sampel pada umumnya dilakukan secara random atau acak, pengumpulan data menggunakan instrumen penelitian, analisis data bersifat kuantitatif/ statistik dengan bertujuan untuk menguji hipotesis yang telah ditetapkan.

Berdasarkan penjelasan di atas, penelitian ini menggunakan pendekatan kuantitatif jenis Explanatory Research untuk mengungkapkan Pengaruh Gaya Kepemimpinan dan lingkungan kerja terhadap disiplin pegawai dengan menggunakan perhitungan variabel tertentu dan indikator tertentu. Dengan tujuan akhir yang ingin dicapai adalah menunjukkan hubungan serta pengaruh perbandingan antar variabel, mendeskripsikan secara statistik dan menaksir atau meramalkan hasil penelitian. Penelitian ini dimaksudkan untuk mengetahui adanya pengaruh antara variabel dependen (variabel terikat) dan variabel independen (variabel bebas).

\section{HASIL DAN PEMBAHASAN}

\section{Uji Hipotesis}

\section{Uji Signifikan Simultan (Uji Statistik F)}

Dalam penelitian ini, uji $\mathrm{F}$ digunakan untuk mengetahui tingkat siginifikansi pengaruh variabel-variabel independen secara bersama-sama (simultan) terhadap variabel dependen. Di duga variabel-variabel bebas yaitu gaya kepemimpinan dan lingkungan kera tidak mempunyai pengaruh yang signifikan secara bersama-sama terhadap variabel terikatnya yaitu disiplin kinerja pegawai.

Dasar pengambilan keputusannya (Ghozali dalam Regina, 2010) adalah dengan menggunakan angka probabilitas signifikansi, yaitu:

a. Apabila probabilitas signifikansi $>0.05$, maka $\mathrm{H}_{0}$ diterima dan $\mathrm{H}_{1}$ ditolak.

b. Apabila probabilitas signifikansi $<0.05$, maka $\mathrm{H}_{0}$ ditolak dan $\mathrm{H}_{1}$ diterima.

Tabel 1.

Hasil Uji Signifikan Simultan (Uji Statistik F)

\begin{tabular}{|c|c|c|c|c|c|}
\hline \multirow[t]{2}{*}{ Model } & \multicolumn{2}{|c|}{$\begin{array}{l}\text { Unstandardized } \\
\text { Coefficients }\end{array}$} & $\begin{array}{c}\text { Standar } \\
\text { dized }\end{array}$ & \multirow[t]{2}{*}{$\mathrm{T}$} & \multirow[t]{2}{*}{ Sig. } \\
\hline & B & Std. Error & Beta & & \\
\hline $\begin{array}{l}\text { (Con } \\
\text { stant) }\end{array}$ & $\begin{array}{c}4,23 \\
6\end{array}$ & 4,068 & & 1,041 & ,312 \\
\hline${ }^{1}$ X.1 & ,242 & ,215 & ,203 & 1,125 & ,276 \\
\hline $\mathrm{X} 2$ & ,914 & 237 & 695 & 3,861 & ,001 \\
\hline
\end{tabular}

a. Dependent Variable: Y

Sumber: Data Yang Diolah SPSS 20 (2019)

Pengujian hipotesis ke tiga $\mathrm{H}_{3}$ Berdasarkan output diatas diketahui nilai signifikan untuk pengaruh $\mathrm{X}_{1}$ dan $\mathrm{X}_{2}$ secara simultan terhadap $\mathrm{Y}$ sebesar $0,005<0,05$ dan nilai $F$ hitung 22,240> $F$ tabel 3,493dan nilai signifikansi 0,000 sehingga dapat disimpulkan bahwa $\mathrm{H}_{3}$ diterima yang berarti terdapat pengaruh $\mathrm{X}_{1}$ dan $\mathrm{X}_{2}$ secara simultan terhadap Y

\section{Uji t (parsial)}

Uji t digunakan untuk melihat atau menguji pengaruh tiap-tiap variabel bebas (gaya kepemimpinan dan lingkungan kerja) secara individual terhadap variabel terikat (disiplin pegawai). Dasar pengambilan keputusan adalah dengan mengambil probabilitas signifikansi yaitu.

a. Apabila angka probabilitas signifikansi > $0,05(\mathrm{~F}$ hitung $<\mathrm{F}$ tabel $)$, maka $\mathrm{H}_{0}$ diterima $\mathrm{H}_{1}$ ditolak. 


\section{Model Summary}

\begin{tabular}{|c|c|c|c|c|}
\hline $\begin{array}{c}\text { Mo } \\
\text { del }\end{array}$ & R & $\begin{array}{c}\text { R } \\
\text { Squ } \\
\text { are }\end{array}$ & $\begin{array}{c}\text { Adjusted } \\
\text { R Square }\end{array}$ & $\begin{array}{c}\text { Std. Error of } \\
\text { the Estimate }\end{array}$ \\
\hline 1 & $\begin{array}{r}51 \\
51\end{array}$ &, 723 &, 691 & 1,238 \\
$\mathrm{a}$
\end{tabular}

a. Predictors: (Constant), X2, X.1

\begin{tabular}{|c|c|c|c|c|c|}
\hline & B & $\begin{array}{l}\text { Std. } \\
\text { Error }\end{array}$ & Beta & & \\
\hline $\begin{array}{l}\text { (Con } \\
\text { stant) }\end{array}$ & $\begin{array}{l}4,2 \\
36\end{array}$ & 4,068 & & $\begin{array}{c}1,04 \\
1\end{array}$ & ,312 \\
\hline X.1 & $\begin{array}{c}, 24 \\
2\end{array}$ & ,215 & 203 & $\begin{array}{c}1,12 \\
5\end{array}$ & ,276 \\
\hline $\mathrm{X} 2$ & $\begin{array}{c}91 \\
4\end{array}$ & 237, & 695, & $\begin{array}{c}3,86 \\
1\end{array}$ & ,001 \\
\hline
\end{tabular}

a. Dependent Variable: $Y$

b. Apabila angka probabilitas signifikansi < 0,05 ( $\mathrm{F}$ hitung $>\mathrm{F}$ tabel) $\mathrm{H}_{0}$ ditolak $\mathrm{H}_{1}$ diterima.

Tabel 2. Hasil Uji t (Parsial) Sumber: Data Yang Diolah SPSS 20 (2019)

a. Nilai T hitung gaya kepemimpinan terhadap disiplin pegawai sebesar 1,125 sementara untuk $\mathrm{t}$ tabel dengan taraf signifikan $\mathrm{a}=0,05$ dan $\mathrm{df}=\mathrm{n}-\mathrm{k}-1$, yaitu $20-2-1=17$ maka didapat $\mathrm{T}$ tabel 2,110. Nilai $\mathrm{T}$ hitung lebih kecil dibandingkan $\mathrm{T}$ tabel, hal ini menunjukan diterimanya $\mathrm{H}_{1}$ yang menyatakan tidak adak ada pengaruh positif dan signifikan antara gaya kepemimpinan terhadap disiplin pegawai.

b. Nilai $\mathrm{T}$ hitung lingkungan kerja terhadap kinerja sebesar 3,861 sementara untuk $\mathrm{T}$ tabel dengan taraf signifikan $\mathrm{a}=0,05 \mathrm{dan} \mathrm{df}=$ n-k-1, yaitu 20-2-1= 17 maka didapat $\mathrm{T}$ tabel 2,110. Nilai $\mathrm{T}$ hitung lebih besar dibandingkan $\mathrm{T}$ tabel, hal ini menunjukan diterimanya $\mathrm{H}_{2}$ yang menyatakan terdapat pengaruh positif dan signifikansi antara lingkungan kerja dan disiplin pegawai.

\section{Analisis Koefisien Determinasi $\left(\mathbf{R}^{2}\right)$}

Hasil koefisiensi determinasi antara gaya kepemimpinan dan lingkungan kerja terhadap disiplin pegawai terdapat pada tabel berikut.

Tabel 3. Koefisien Determinasi $\left(\mathbf{R}^{2}\right)$

Sumber: Data Yang Diolah SPSS 20 (2019)
Hasil koefisiensi determinasi antara gaya kepemimpinan dan lingkungan kerja terhadap disiplin pegawai dapat dilihat hasilnya pada tabel berikut. Hasil Analisis :

a. $\mathrm{R}$ yang disebut juga dengan koefisiensi korelasi, menunjukan bahwa hubungan antara variabel bebas (gaya kepemimpinan dan disiplin kerja ) dan variabel terikat (kinerja karyawan) adalah, 85,1\% (0,851)

b. Angka $\mathrm{R}$ square atau disebut jugaa dengan koefisiensi determinasi. Dari tabel dapat dibaca $\mathrm{R}$ square $\left(\mathrm{R}^{2}\right)$ adalah $72,3 \%(0,723)$. Artinya sebesar $72,3 \% \quad(0,723)$ disiplin karyawan dipengaruhi oleh variabel gaya kepemimpinan dan lingkungan kerja sedangkan sisanya sebesar $27,7 \%$ dipengaruhi oleh faktor lain.

c. Standart error of the estimate merupakan kesalahan standar dari penaksiran 1,238.

\section{KESIMPULAN}

Berdasarkan dari analisis dan hasil analisis data penelitian tentang pengaruh gayakepemimpinan dan lingkungan kerja terhadap disiplin pegawai maka dapat disimpulkan bahwa:

1. Tidak terdapat pengaruh yang positif dan signifikan antara gaya kepemimpinan terhadap disiplin pegawai, hal ini dibuktikan dengan hasil uji regresi linier berganda yang menghasilkan $\mathrm{T}$ hitung lebih kecil dari $\mathrm{T}$ tabel. Dengan demikian maka dapat disimpulkan bahwa rumusan hipotesis (H1) menyatakan bahwa tidak adanya pengaruh signifikan dari gaya kepemimpinan terhadap disiplin pegawai adalah ditolak. Sebalikanya rumusan hipotesis (H0) yang menyatakan adanya pengaruh signifikan dari gaya kepemimpinan terhadap disiplin pegawai adalah diterima.

2. Terdapat pengaruh yang positif dan signifikansi antara lingkungan kerja terhadap disiplin pegawai, hal ini dapat dibuktikan hasiil uji regresi liner berganda yang menghasilkan nilai $\mathrm{T}$ hitung lebih besar dari $\mathrm{T}$ tabel. Dengan demikian maka dapat disimpulkan bahwa (H2) menyatakan bahwa terdapat pengaruh signifikansi dari lingkungan kerja terhadap disiplin pegawai adalah diterima. Sebaliknya rumusan hipotesis (H0) yang menyatakan adanya pengaruh signifikan dari lingkungan kerja terhadap disiplin pegawai adalah ditolak.

3. Hasil pengujian hipotesis telah membuktikan terdapat pengaruh antara gaya 
kepemimpinan dan lingkungan kerja secara bersama-sama terhadap disiplin pegawai. Pengujian membuktikan bahwa gaya kepemimpinan dan lingkungan kerja memiliki pengaruh positif terhadapdisiplin pegawai. Dilihat dari perhitungan yang telah dilakukan dan diperoleh nila $\mathrm{F}$ hitung lebih kecil dari 0,05 , yang berarti bahwa hipotesis dalam penelitian ini menerima $\mathrm{H} 1$ dan menolak H0. Dalam penelitian ini gaya kepemimpinan dan lingkungan kerja berpengaruh positif dan signifikan terhadap disiplin pegawai.

\section{SARAN}

Memperhatikan adanya beberapa keterbatasan seperti yang telah disampaikan maka bagi penelitian ini perlu memperhatikan beberapa saran yaitu.

a. Hasil penelitian yang dilakukan, variabel yang dominan dalam mempengaruhi disiplin pegawai adalah lingkungan kerja. Diharapkan Kantor Kecamatan Kanor Kabupaten Bojonegoro dapat mempertahankan disiplin pegawai karena lingkungan kerja memiliki konstribusi yang dominan, melakukan penyempurnaan kuisioner ini,serta melakukan pemilihan waktu yang tepat ketika menyabar kuisioner.

b. Peneliti selanjutnya yang ingin meneliti atau melanjutkan penelitian ini dengan mencari variabel lain . Dan dalam pengisian koesioner responden bisa lebih memaksimalkan dan menentukan jumlah responden.

c. Kantor Kecamatan Kanor berdasarkan hasil penelitian bahwa tingkat disiplin kerja masih rendah, oleh karena itu, Kantor Kecamatan meningkatkan disiplin kerja terhadap kinerja pegawai.

\section{DAFTAR PUSTAKA}

Azwin Mahmud (2017) Pengaruh Gaya Kepemimpinan Camat Labuhan Ratu Terhadap Penegakkan Disiplin Pegawai, FakultasIlmuSosisaldanPolitik UniversitasLampung Bandar Lampung

Eliyanto (2018) Pengaruh Motivasi Kerja Dan Lingkungan Kerja Terhadap Kinerja Guru Sma Muhammadiyah Di Kabupaten Kebumen, Volume

3,InstitutNahdlotulUlama Kebumen
Istiqomah Qodriani Fajrin , Heru Susilo (2018) Pengaruh Gaya Terhadap Kinerja Karyawan Dengan Motivasi Kerja Sebagai Variabel Intervening, Volume 18,FakultasIlmuAdministrasi Universitas Brawijaya Malang

Izaz Dany Afianto, Hamidah Nayati Utami (2017) Pengaruh Disiplin Kerja Dan Komunikasi Organisasi Terhadap Kepuasan Kerja Dan Kinerja Karyawan(Studi pada Karyawan Divisi Marketing PT. Victory SInternational Futures Kota Malang), Volume 52, FakultasEkonomiAdministrasi Universitas Brawijaya Malang

Mohammad ImanTindowPeggy A. MekelGreis M. Sendow (2014) Disiplin Kerja, Motivasi Dan Kompensasi Pengaruhnya Terhadap Kinerja Karyawan Pada Pt. Bank Sulut Cabang Calaca, Volume 2,FakultasEkonomidanBisnis,

JurusanManajemenUniversitasSamratula ngi Manado

Rahma Fitha (2017) Pengaruhan Kepemimpian Dan Disiplin Kerja Terhadap Kinerja Karyawan, ProdiManajemen FakultasEkonomidanBisnis

Reza Ananto (2014)Analisis Pengaruh Gaya Kepemimpinan, Motivasi Dan Disiplinkerja Terhadap Kinerja Pegawai,Fakultas Ekonomi danBisnisUniversitasDiponegoro

Riza Widyanata, (2016) Pengaruh Lingkungan Dan Kemampuan Kerja Terhadap Kinerja Karyawan Pt. Ronadamar Sejahtera Cabang Bandung, Volume 1, FakultasEkonomi Universitas Pendididikan Indonesia

Yuliyanti, Istiatin, Ida Aryati (2017), Pengaruh Insentif, Disiplin Kerja, Dan Komunikasi Terhadap Kinerja Karyawan Bagian Sewing Pt. Pelita Tomangmas Karanganyar,Volume

18,FakultasEkonomiUniversitas Islam Batik Surakarta. 